\title{
Identification of Nonvisual Photomotor Response Cells in the Vertebrate Hindbrain
}

\author{
David Kokel, ${ }^{1,2}$ Timothy W. Dunn, ${ }^{3}$ Misha B. Ahrens, ${ }^{3}$ Rüdiger Alshut, ${ }^{5}$ Chung Yan J. Cheung, ${ }^{1,2}$ Louis Saint-Amant, ${ }^{6}$ \\ Giancarlo Bruni, ${ }^{1,2}$ Rita Mateus, ${ }^{1,2}$ Tjakko J. van Ham, ${ }^{1,2}$ Tomoya Shiraki, ${ }^{4}$ Yoshitaka Fukada, ${ }^{4}$ Daisuke Kojima, ${ }^{4}$ \\ Jing-Ruey J. Yeh, ${ }^{1}$ Ralf Mikut, ${ }^{5}$ Johannes von Lintig, ${ }^{7}$ Florian Engert, ${ }^{3}$ and Randall T. Peterson ${ }^{1,2}$ \\ ${ }^{1}$ Cardiovascular Research Center and Division of Cardiology, Department of Medicine, Massachusetts General Hospital, Harvard Medical School, \\ Charlestown, Massachusetts 02129, ${ }^{2}$ Broad Institute, Cambridge, Massachusetts 02142, ${ }^{3}$ Department of Molecular and Cellular Biology, Harvard University, \\ Cambridge, Massachusetts 02138, ${ }^{4}$ Department of Biophysics and Biochemistry, Graduate School of Science, The University of Tokyo, Tokyo 113-0033, \\ Japan, ${ }^{5}$ Institute for Applied Computer Science, Karlsruhe Institute of Technology, D-76128 Karlsruhe, Germany, ${ }^{6}$ Université de Montréal, Montréal, \\ Quebec H3C 3J7, Canada, and 7Department of Pharmacology, School of Medicine, Case Western Reserve University, Cleveland, 0 hio 44106
}

Nonvisual photosensation enables animals to sense light without sight. However, the cellular and molecular mechanisms of nonvisual photobehaviors are poorly understood, especially in vertebrate animals. Here, we describe the photomotor response (PMR), a robust and reproducible series of motor behaviors in zebrafish that is elicited by visual wavelengths of light but does not require the eyes, pineal gland, or other canonical deep-brain photoreceptive organs. Unlike the relatively slow effects of canonical nonvisual pathways, motor circuits are strongly and quickly (seconds) recruited during the PMR behavior. We find that the hindbrain is both necessary and sufficient to drive these behaviors. Using in vivo calcium imaging, we identify a discrete set of neurons within the hindbrain whose responses to light mirror the PMR behavior. Pharmacological inhibition of the visual cycle blocks PMR behaviors, suggesting that opsin-based photoreceptors control this behavior. These data represent the first known light-sensing circuit in the vertebrate hindbrain.

\section{Introduction}

How the nervous system senses and responds to light is a fundamental question in neuroscience.

Photobiology has traditionally focused on visual pathways (Ridge et al., 2003). However, nonvisual photo-sensation also plays an important role in animal physiology and behavior (Lucas et al., 1999; Berson et al., 2002; Hattar et al., 2003; Zaidi et al., 2007; Noseda et al., 2010). The majority of research on nonvisual photic behaviors has been dedicated to understanding circadian rhythms, which are controlled via hormones over relatively long time scales (hours to days) (Reppert and Weaver, 2001). Beyond

Received Aug. 1, 2012; revised Jan. 2, 2013; accepted Jan. 8, 2013.

Author contributions: D. Kokel, T.W.D., M.B.A., R.A., C.Y.J.C., L.S.-A., G.B., R. Mateus, T.J.v.H., J.-R.J.Y., F.E., and R.T.P. designed research; D. Kokel, T.W.D., M.B.A., R.A., C.Y.J.C., L.S.-A., G.B., R. Mateus, T.J.v.H., and J.-R.J.Y. performed research; T.W.D., M.B.A., R.A., T.S., Y.F., D. Kojima, R. Mikut, J.v.L., and F.E. contributed unpublished reagents/analytic tools; D. Kokel, T.W.D., M.B.A., R.A., C.Y.J.C., L.S.-A., G.B., R. Mateus, T.J.v.H., J.-R.J.Y., F.E., and R.T.P. analyzed data; D. Kokel and R.T.P. wrote the paper.

This work was supported by National Institutes of Health Grants K01MH091449 to D. Kokel, R01MH086867 and R21MH085205 to R.T.P., and DP1 NS082121 and R01DA030304 to T.W.D. and F.E. This work was supported in part by Grants-in-Aid for Scientific Research from Japan Society for the Promotion of Science to Y.F. and D. Kojima, T.W.D. was supported by the National Science Foundation Graduate Research Fellowship. M.B.A. was supported by a Sir Henry Wellcome Postdoctoral Fellowship from the Wellcome Trust. R.T.P. was supported by the Charles and Ann Sanders MGH Research Scholar award. We thank John Dowling and members of our research groups for encouragement and advice.

The authors declare no competing financial interests.

Correspondence should be addressed to either Dr. David Kokel or Dr. Randall T. Peterson, Cardiovascular Research Center and Division of Cardiology, Department of Medicine, Massachusetts General Hospital, Harvard Medical School, 149 13th Street, Charlestown, MA 02129, E-mail: dkokel@cvrc.mgh.harvard.edu or peterson@cvrc.mgh.harvard.edu.

DOI:10.1523/JNEUROSCI.3689-12.2013

Copyright $\odot 2013$ the authors $\quad 0270-6474 / 13 / 333834-10 \$ 15.00 / 0$ circadian rhythms, nonvisual pathways can also control motor behaviors on a short time scale (seconds) (Becker and Cone, 1966; Harth and Heaton, 1973; Heaton and Harth, 1974; Peirson et al., 2009). For example, it has been recently shown that deep brain photoreceptors control light-seeking behaviors in zebrafish larvae (Fernandes et al., 2012). Such behaviors are a fundamental aspect of how the vertebrate nervous system responds to light, but remain poorly understood at the cellular and molecular levels.

The retina is the only known light-detecting organ in mammals. However, some birds and reptiles express specialized extraocular photoreceptors in various organs, including the pineal complex, deep brain, and skin (Yoshikawa et al., 1998; Vigh et al., 2002). A number of photopigments have been identified in these extraocular tissues, including pinopsin (Okano et al., 1994; Max et al., 1995), melanopsin (Provencio et al., 1998), parapinopsin (Blackshaw and Snyder, 1997), exo-rhodopsin (Mano et al., 1999), vertebrate-ancient opsin (Val-opsin) (Kojima et al., 2000), and neuropsin (Nakane et al., 2010). These opsins are thought to enable nonvisual photodetection (Vigh et al., 2002). However, their precise roles in physiology and behavior are poorly understood. Here, we have investigated the phenotypic, cellular, and molecular mechanisms of the zebrafish photomotor response (PMR) behavior using a combination of genetic, behavioral, electrophysiological, and calcium imaging techniques. We find an unexpected circuit in the zebrafish hindbrain that is required for nonvisual light-driven motor behaviors. These data implicate a new locus of photosensitive hindbrain neurons controlling nonvisual light detection and motor behaviors in vertebrates. 


\section{Materials and Methods}

\section{Fish maintenance and aquaculture}

Zebrafish embryos were collected from group mating wild-type zebrafish (Ekkwill). Embryos of either sex were raised in HEPES (10 mM) buffered E3 media in a dark incubator at $28^{\circ} \mathrm{C}$.

\section{Behavioral recordings and data analysis}

Grouped. The PMR assay was performed as described previously (Kokel et al., 2010). Briefly, groups of 8-10 embryos were distributed into the wells of flat-bottom black 96-well plates. A total of 1000 frames of digital video were recorded at $30 \mathrm{fps}$. The motion index was calculated by frame differencing. "Excitation scores" are calculated by taking the 75th percentile of the motion index during indicated phases of the PMR behavior. Measurements and analysis were performed using the MetaMorph and Matlab software packages.

Individual. To quantify individual zebrafish movements, we developed an image-processing pipeline with the following steps: Gaussian deblurring was used to reduce camera noise. Hough circle detection was used to identify a region of interest (ROI) around the chorion surrounding each embryo. The ROI for each animal is dynamically tracked through all video frames. Movement is quantified by frame differencing and normalized relative to the ROI intensity. Manual inspection of the movies revealed that high-magnitude, low-frequency peaks in the motion index correlated with coiling events in the movies, so these peaks were defined as coiling events by the algorithm. Similarly, lowmagnitude high-frequency peaks correlated with swimming events, so these peaks were defined as swimming by the algorithm. Coiling events within swimming events were also detected. Videos were processed using the MATLAB software package and the open source MATLAB Toolbox Gait-CAD (Mikut, 2008). The total calculation time of the whole processing pipeline, including fish finding, tracking, and classification, does not exceed $1.5 \mathrm{~min}$ for each movie on a usual desktop computer. We also developed a stand-alone graphical user interface providing easy application, batch processing of the video data as well as automated report generation. The software is available from the authors upon request.

Statistical analysis. We used one-way ANOVA and the Tukey HSD post hoc test to test for significant differences between groups, generate $95 \%$ confidence intervals, and identify groups with significantly different means. For groups with significant differences, we used the two-tailed $t$ test to test the null hypothesis and calculate the $p$ value. Statistical analyses were performed using the anova 1, multcompare, and ttest 2 functions provided by the MATLAB statistics toolbox. All error bars represent SDs, unless otherwise noted.

\section{Morpholino gene knockdown}

All morpholinos in this study were obtained from GeneTools. Morpholinos used for this study were as follows: valA (5' ${ }^{\prime}$ TTTGT GAAGA CCTTT CTGAG TTTGC-3'), valB (5' -TATAT GACTA ACCTT TCTGA GCTTC- $\left.3^{\prime}\right)$, valB2 (5'-GAGTG TTCGA TACCT ATTAA GCATA- $\left.3^{\prime}\right)$, exorho (5' -CGGTGTTGTAGTGTGCTCACCGCCG-3'), opn4.1 (CTC TCCATGAAGAGTGATGGCTCAT), opn4b (CAGCCCTGTCCATACACAACACACA), and opn4xb (ACATCCTGAAAACACACACAG AGAA). Morpholino efficacy was verified by PCR identification of splicing defects in the targeted genes, except for the opn4.1 morpholino, which targets the opn4.1 ATG translation start site. The yolks of singlecell, stage-fertilized embryos were injected with $1 \mathrm{nl}$ of the $0.5 \mathrm{~mm}$ morpholino solutions (5 ng per animal) or as noted.

\section{Confocal analysis}

Live imaging of embryonic zebrafish brain was performed as previously described (Lowery and Sive, 2005). Briefly, zebrafish embryos were embedded in $0.7 \%$ low melting agarose. The agarose enabled movements to be visualized in digital videos while preventing animals from swimming away. Images were captured on an inverted microscope (AxioObserver Z1; Zeiss) using the LSM700 scanning system (Zeiss, $488 \mathrm{~nm}$ laser lines) and a $20 \times$ objective (Zeiss). Embryos globally expressed a GFP transgene (Krovel and Olsen, 2002) to enable their visualization under the $488 \mathrm{~nm}$ laser stimulus illumination.

\section{Photic stimuli}

Light stimuli were generated with a $300 \mathrm{~W}$ xenon bulb housed in a Sutter Lambda LS illuminator and delivered to the well 10 and $20 \mathrm{~s} \mathrm{(or} 13$ and $23 \mathrm{~s}$ ) after the start of each video. A cold mirror (reflectance between 300 and $700 \mathrm{~nm}$ ) on the Sutter illuminator was used to block wavelengths outside of this range. Stimulus wavelengths were restricted using a quadband beamsplitter (Semrock; DA/FI/TR/Cy5-4X4M-B-ZHE) and four single band exciters (center wavelength/bandwidth): 387/11, 485/20, 560/25, and 650/13 (Semrock; Brightline FF01). Light intensity was measured using a PM100D power meter attached to a S120VC photodiode power sensor (Thorlabs). Intensity of the full strength white light stimulus on the embryos was $67 \mu \mathrm{W} / \mathrm{mm}^{2}$. The intensities of violet $(387 \mathrm{~nm})$ and red $(650 \mathrm{~nm})$ wavelengths were $3 \mu \mathrm{W} / \mathrm{mm}^{2}$. The intensities of blue $(485 \mathrm{~nm})$ and green $(560 \mathrm{~nm})$ wavelengths were $15 \mu \mathrm{W} / \mathrm{mm}^{2}$. High intensity violet $\left(405 \mathrm{~nm} ; 600 \mu \mathrm{W} / \mathrm{mm}^{2}\right)$ and $\operatorname{red}\left(650 \mathrm{~nm} ; 23 \mu \mathrm{W} / \mathrm{mm}^{2}\right)$ stimuli were generated with pen style laser pointers $(<5 \mathrm{~mW})$, and their intensities were reduced using neutral density filters. For comparison, ambient light in the laboratory was $\sim 1 \mu \mathrm{W} / \mathrm{mm}^{2}$ and direct sunlight on rare sunny day in Boston was $667 \mu \mathrm{W} / \mathrm{mm}^{2}$.

\section{Dissections and spinalized preparations}

Dissections were performed under the same general conditions as described previously (Downes and Granato, 2006). To remove the eyes and pineal gland, the zebrafish hindbrain was severed between the anterior hindbrain ventricle and the otic vesicle, at approximately the level of rhombomere 3-4, completely removing all midbrain and forebrain structures, including the eyes and pineal complex (Asaoka et al., 2002). Data were collected 1-3 h after surgery; however, the decapitated preparations were surprisingly robust, responding to stimuli for $>12 \mathrm{~h}$ after transection. Surgeries were performed under the microscope with forceps and a sharp razor blade after brief ice anesthesia. Dissected preparations were prepared and maintained in $1 \times$ Ringer's solution $(116 \mathrm{~mm}$ $\mathrm{NaCl}, 2.9 \mathrm{~mm} \mathrm{KCl}, 1.8 \mathrm{~mm} \mathrm{CaCl}$, and 5 mm HEPES, pH 7.2).

\section{Electrophysiology}

We devised a $14 \mathrm{~min}$ recording protocol in which we recorded from a muscle cell in partially paralyzed embryos aged $32-36 \mathrm{~h}$ post fertilization (hpf). Lights were turned off at the beginning of the recording, and the responsiveness of the embryos to photo and tactile stimuli was assessed. Most of the embryos (11 of 15) also showed spontaneous fictive motor activity during the period of dark adaptation.

Myocyte recordings were obtained from embryos aged 32-36 h at room temperature using methods previously described (Hamill et al., 1981; Ribera and Nüsslein-Volhard, 1998; Drapeau et al., 1999). Embryos were anesthetized by adding Tricaine $(0.02 \% \mathrm{w} / \mathrm{v})$ to our Evans extracellular recording solution: $134 \mathrm{~mm} \mathrm{NaCl}, 2.9 \mathrm{~mm} \mathrm{KCl}, 2.1 \mathrm{~mm}$ $\mathrm{CaCl}_{2}, 1.2 \mathrm{~mm} \mathrm{MgCl}_{2}, 10 \mathrm{~mm}$ glucose, and $10 \mathrm{~mm}$ HEPES, adjusted to $\mathrm{pH}$ 7.8 with $\mathrm{NaOH}$. The embryos were pinned to a $35 \mathrm{~mm}$ Sylgard-coated dish, and the skin overlying several somites was removed. The solution was replaced by gravity perfusion $(1-2 \mathrm{ml} / \mathrm{s})$ of anesthetic-free Evans, which contained $6 \mu \mathrm{M}$ D-tubocurarine to partially paralyze the preparation and enable recording from muscle cells under the whole-cell patchclamp configuration. The internal recording solution contained the following: $116 \mathrm{~mm} \mathrm{~K}$-gluconate, $16 \mathrm{~mm} \mathrm{KCl,} 2 \mathrm{mM} \mathrm{MgCl}_{2}, 10 \mathrm{~mm}$ HEPES, 10 m EGTA, at pH 7.2 with $\mathrm{KOH}$ to which we added $0.1 \%$ SulforhodamineB for cell identification. Borosilicate glass electrodes had resistances of 4-6 M $\Omega$ when filled with internal recording solution. Recordings were made with an Axopatch 200B amplifier (Molecular Devices) low pass filtered at $2 \mathrm{kHz}$ and sampled at $10 \mathrm{kHz}$. The microscope used was a Zeiss examiner A1, and fine pipette movement was controlled with a Sutter MPC-200 manipulator system. Tactile stimuli were delivered by ejecting solution from a pipette with a $25 \mu \mathrm{m}$ opening where the pressure and duration were set via a picospritzer III (Parker). Photo stimuli were delivered using the built-in illumination from the microscope $(100 \mathrm{~W})$ where the duration was limited at $1 \mathrm{~s}$ using a uniblitz shutter (Optikon) triggered by a TTL pulse, this illumination was enhanced with a camera flash (Vivitar, $600 \mathrm{CR}$ ) occurring at the beginning of the $1 \mathrm{~s}$ TTL triggered time period. Data acquisition and TTL triggering of stimuli were achieved with pClamp 10 software using a Digidata 1440A 
interface. The initial data analysis was done with Clampfit 10, and figures were prepared using Adobe Illustrator.

\section{Calcium imaging}

A custom-built two-photon microscope (Denk et al., 1990) was used to monitor neuronal activity in the hindbrain of 32-38 hpf zebrafish. The embryos expressed the genetically encoded calcium indicator GCaMP2 under the pan-neuronal $\mathrm{HuC}$ promoter, and were homozygous nacre in a WIK wild-type background. Embryos were treated in phenylthiourea to remove pigmentation and were prescreened before imaging for robust responses to photic stimuli. Embryos were then dechorionated and paralyzed by bathing them in $1 \mathrm{mg} / \mathrm{ml}$ bungarotoxin (Invitrogen) solution and creating a small lesion at the tip of the tail with a forceps for better access to the internal tissues. Paralyzed embryos were side-mounted in 2\% agarose and covered in standard E3 fish water in preparation for imaging. During imaging experiments, one second of blue light was delivered by an LED (Thorlabs) 3 times at $30 \mathrm{~s}$ intervals. This was repeated for the next imaging plane with a 12 min delay to allow the PMR to recover. Because of leakage of the blue light to the photomultiplier tube, the photomultiplier tube was switched off during blue light stimulation, so that measurement of GCaMP2 fluorescence commenced upon offset of the stimulus.

Fluorescence movies were analyzed with custom written Matlab software as described previously (Ahrens et al., 2012). First, a square ROI, half the size of a neuron, is swept over all locations of the imaging plane. At each location, a fluorescence time-series, averaged over the ROI, is extracted and converted to a statistic for the "peaky-ness" of the fluorescence signal at that point. If $f(x, y, t)$ is the fluorescence of the pixel at $x, y$ at time $t$, and $f_{\text {squ }}(x, y, t)$ is the average fluorescence of the box centered at pixel $x, y$, and $f_{\text {avg }}$ is the average fluorescence over space and time for the entire image sequence, then the statistic was defined to be as follows:

$\mathrm{m}=(x, y)=<\left[\mathrm{f}_{\mathrm{squ}}(x, y, t) /<\left(\mathrm{f}_{\mathrm{squ}}(x, y, t)\right\rangle\right.$

where $\langle\ldots\rangle$ denotes the average over $t$. This measure was chosen because it bears resemblance to the usual $\mathrm{dF} / \mathrm{F}$ but contains an offset to counteract the undesired amplification of noise; the third power was chosen because it nonlinearly converts peaks in the fluorescence signal to larger values of the statistic. This measure (one of several tested) yielded spatial signal maps $m(x, y)$, which tended to be at least as sensitive as sets of ROIs selected manually from observation of the raw and dF/F movies. These signal maps were thresholded, and points of interest were found at the approximate centers of the peaks of $m(x, y)$ by first smoothing with a 2D Gaussian and then finding the local maxima of the smoothed map. These formed the centers of the final ROIs (see Fig. $5 e$ ). These ROIs were then checked manually for any obvious artifacts. For the representative slice shown in Figure 5b, automatically detected ROIs were hand segmented to match the shape of each neuron associated with a given ROI. The regions indicated by dotted red lines contain many detected ROIs that were associated with fiber tracts rather than individual somata. For constructing the standardized ROI spatial distribution map, automatically detected ROIs from 4 fish with complete image stacks through at least one half of the brain were assigned coordinates relative to the loca-
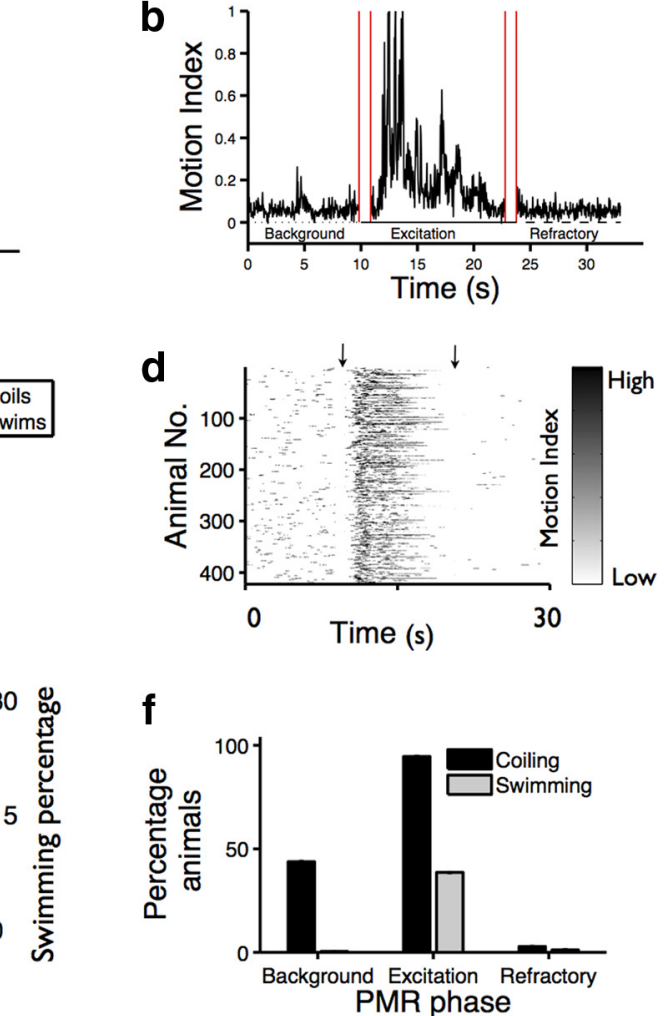

$$
\left.\left.+\mathrm{f}_{\mathrm{avg}}\right)\right]^{\wedge} 3>
$$

Figure 1. Light stimuli elicit stereotyped photomotor behaviors in zebrafish embryos. Plots showing the combined motor
activity of 10 dark-adapted zebrafish embryos in response to one $(\boldsymbol{a})$ or two $(\boldsymbol{b})$ light stimuli (red bars). $\boldsymbol{c}$, Plot showing the motor activity of an individual zebrafish during the PMR assay. High-magnitude, low-frequency peaks represent coiling events $(\mathbf{O})$ whereas low-magnitude, high-frequency peaks represent swim events (gray bar). Paired vertical lines at 10 and 23 s are stimulus Par a bar plot showing the percentage of animals exhibiting coiling and swimming behaviors ( $y$-axis) during the indicate phase ( $x$-axis). The differences between the percentages of animals coiling during each phase are significant: $p<0.001$. The percentage of animals swimming during the excitation phase is significantly more than during the background and refractory phases: $p<0.001$

tion of the first occipital nerve in rhombomere 8. In this 3D coordinate system, each ROI was assigned a rostrocaudal distance along the ventral surface of the brain relative to the nerve, a dorsoventral distance along the line normal to its position on the previously defined rostrocaudal axis, and a mediolateral distance from the lateral edge of the brain. Each ROI was then plotted onto an average intensity projection of a standard $36 \mathrm{hpf}$ brain. The density metric used in Figure $5 d$ was calculated by averaging ROI densities across all sampled imaging planes from three additional fish that were exposed to all three conditions. For each plane, ROI density was calculated by dividing the number of detected ROIs by the volume of labeled neurons in the plane (area of labeled neurons $\times 1 \mu \mathrm{m}$ ).

\section{Results}

The PMR is a stereotyped behavior of reproducible kinematic events

Recently, we discovered the PMR, a robust series of motor behaviors triggered by photic stimuli in embryonic zebrafish (Kokel et al., 2010). In the PMR behavior, dark-adapted zebrafish embryos (30 hpf) respond to a bright pulse of light with a striking series of stereotyped motor behaviors within the chorion (Fig. 1a). The PMR can be divided into different phases, including background, excitation, and inactive/refractory phases (Fig. $1 a, b$ ). Before the stimulus, individual animals move infrequently with spontaneous coiling movements (Fig. 1a,b). Then, the stimulus elicits vigorous motor excitation lasting for $\sim 5-7 \mathrm{~s}$. After excitation, the 


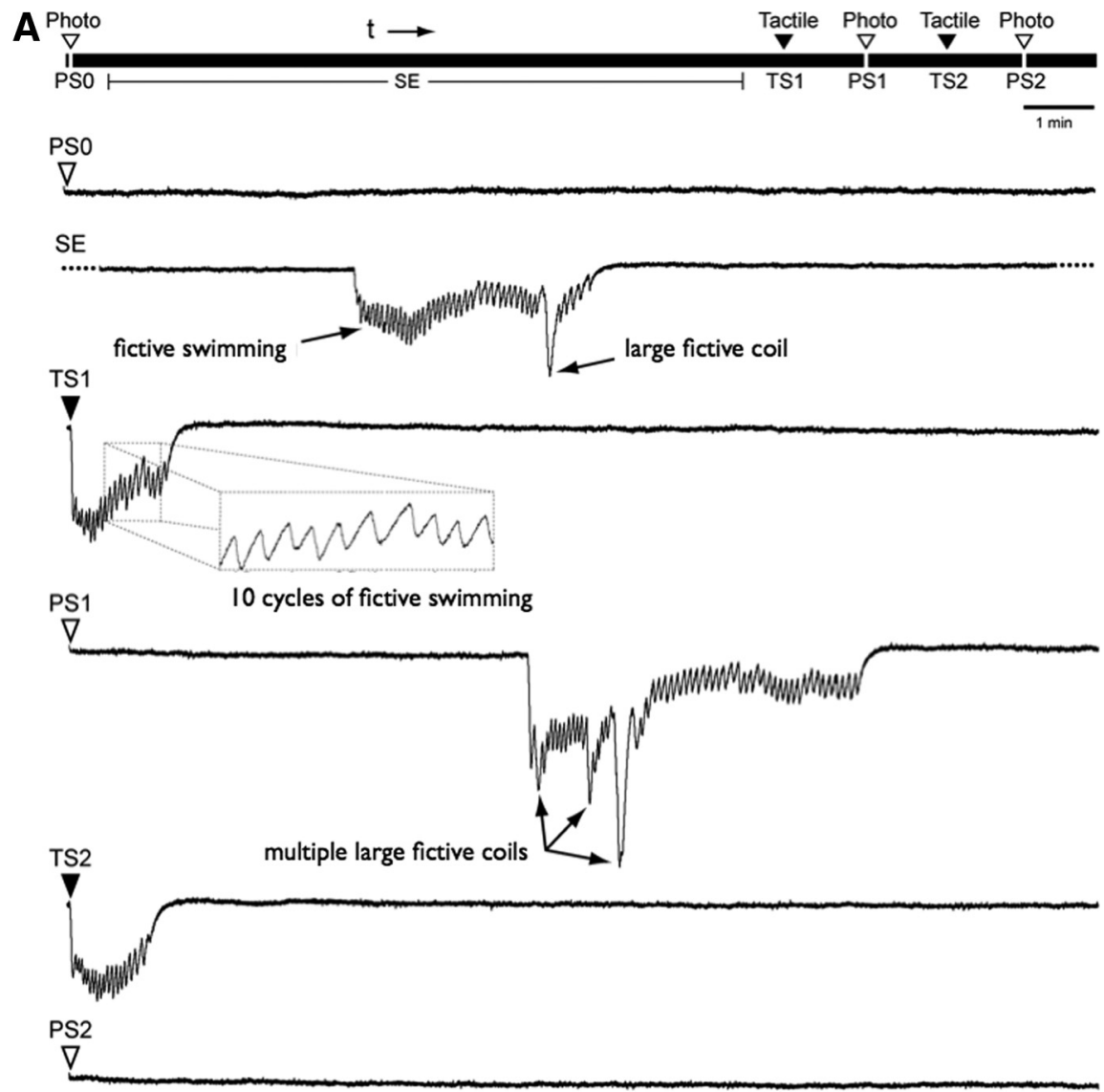

B

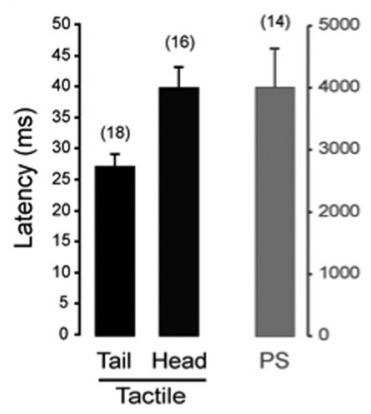

C

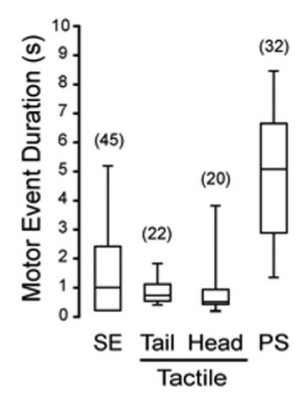

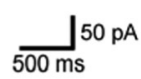

D

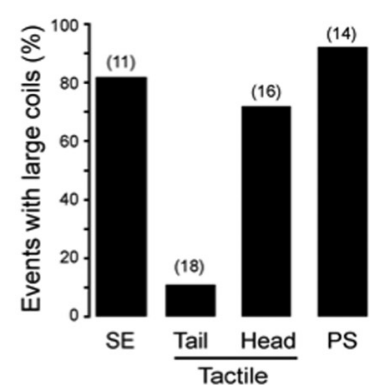

Figure 2. Motor circuits are strongly recruited during PMR excitation. Muscle cells were recorded in paralyzed embryos to assay fictive motor output. $\boldsymbol{A}$, Top diagram, The experimental procedure. The lines below show representative traces that begin upon stimulus triggering. Embryos are photostimulated at the beginning of the experiment (PSO), followed by 10 min of dark adaptation with occasional spontaneous events (SE); at the 11th minute, the embryos receive a tactile stimulus (TS1), followed by a photostimulus (PS1), another tactile stimulus (TS2), and a final photostimulus (PS2). B , Latency graph for tail and head tactile stimuli and photo stimuli (PS). There is a 100-fold change in the gray axis. C, Box-plot showing event duration for spontaneous, tactile, and photo stimuli-evoked events. D, Percentage of events exhibiting large struggling coils in spontaneous, tactile, and photo-evoked events. The numbers in parentheses represent the total number of motor events analyzed.

animals enter an inactive/refractory phase, characterized by less than background levels of activity and unresponsiveness to a second pulse of light (Fig. 1a,b). Interestingly, it takes $\sim 10$ min of dark readaptation between stimuli for animals to respond to a second pulse of light (Fig. $1 b$ ).

We find that individual animals undergoing the PMR exhibit at least two types of motor events (coiling and swimming), which can be discriminated based on visual inspection of behavioral recordings. Coiling describes large alternating contractions that are likely to be analogous to turning events in older animals. By contrast, swimming describes high-frequency contractions that serve to propel the animal in the forward direction. Using a custom image-processing algorithm to analyze the behavior of individual animals, we find that swimming and coiling events can be discriminated via the amplitude and duration of peaks in the motion. Coiling events correspond to large-magnitude, low-frequency peaks, whereas swimming events correspond to low-magnitude, high-frequency peaks (Fig. 1c).

Overall, we identified 1540 coiling events and 19,775 swimming events in an analysis of 425 animals during the PMR behavior. The distribution of these events shows that motor activity increases dramatically after stimulus presentation (Fig. 1d). After a median of $2.2 \mathrm{~s}$ after the start of the stimulus presentation, coiling frequency increases $\sim 10$-fold, from 0.07 coils/s to 0.82 coils/s, for a median duration of $0.8 \mathrm{~s}$. Swimming behaviors, which are only rarely observed before the stimulus in only $0.5 \%$ of animals, are observed in $38 \%$ of animals after the stimulus and last for a median duration of $3.3 \mathrm{~s}$ (Fig. $1 e, f)$. Interestingly, the peak of swimming behaviors occurs $1.75 \mathrm{~s}$ after the peak of coiling behaviors, indicating that the PMR excitation phase can be subdivided into an early period of rapid coiling, followed by a later period of prolonged swimming, although coils are not always followed by swimming (Fig. 1e,f). By the end of this excitation phase, coiling behaviors decrease to 0.02 coils/s, $\sim 3$-fold lower than background levels, and animals do not respond to a second pulse of light (Fig. $1 b-d$ ). These results indicate that the PMR behavior is a stereotyped series of reproducible coiling and swimming events followed by a long period of inactivity.

\section{Motor circuits are strongly recruited during PMR excitation}

To understand the mechanism underlying the series of coiling and swimming events that occur during the PMR, we devised a $14 \mathrm{~min}$ electrophysiological recording protocol in which we recorded responses from a muscle cell in partially paralyzed embryos aged 32-36 hpf. Lights were turned off at the beginning of the recording, and the responsiveness of the embryos to photo and tactile stimuli (tail or head) was assessed. Embryos were dark adapted for $10 \mathrm{~min}$ and then tested again with photo and tactile stimuli (Fig. 2). Consistent with our video analysis, we find two types of electrophysiological events during head touch, tail touch, and PMR assays (low-frequency, large amplitude events and highfrequency low amplitude events), consistent with fictive coiling 
and swimming, respectively (Fig. 2A). None of the embryos responded to the light stimuli before dark adaptation $(n=$ $15)$, whereas they all responded to tactile stimulation. Most of the embryos showed spontaneous fictive motor excitation during the period of dark adaptation (11 of 15). The mean latency to tail and head tactile stimulus responses were significantly different from each other at $27 \pm 2 \mathrm{~ms}$ $(n=18)$ and $38 \pm 4 \mathrm{~ms}(n=16)$, respectively $(p<0.01)$, whereas the mean latency of responses to photo stimulation in the same animals was a full two orders of magnitude greater than either head or tail latencies at $3988 \pm 612 \mathrm{~ms}(n=14, p<$ 0.001 ) (Fig. $2 B$ ). This massive increase in latency suggests that the recruitment of the motor system by light stimulation may be dependent on a very slow cellular and/or molecular mechanism that is different from the mechanisms controlling the touch response. The PMR included a high percentage of fictive coils $(92 \%, n=$ 18 ), whereas spontaneous motor output consisted of $82 \%(n=11)$ fictive coils; head touch elicited fictive coils in $72 \%$ $(n=18)$ of trials, and tail touch only $11 \%$ $(n=18)$ (Fig. 2D). The mean duration of fictive photomotor events at $4907 \pm 337$ ms was significantly longer than all other forms of motor activity with $675 \pm 179$, $818 \pm 64$, and $1301 \pm 168 \mathrm{~ms}$, respectively, for head, tail, and spontaneous motor events ( $p<0.001$; Fig. $2 C)$. These long duration activity patterns, which consistently include struggling coils, suggest a very strong recruitment of the motor circuits during PMR excitation.

\section{The PMR is a nonvisual motor behavior}

The developmental time course of several motor behaviors in the zebrafish embryo have been well characterized. For example, spontaneous contractions develop at $17 \mathrm{~h}$ after fertilization (Saint-Amant and Drapeau, 1998). In dechorionated animals, the touch response develops at $21 \mathrm{hpf}$ and touch-evoked swimming develops at 26 hpf (Saint-Amant and Drapeau, 1998). Zebrafish embryos hatch between 48 and $60 \mathrm{hpf}$ and develop their first visual behaviors, including the optokinetic reflex and the visual startle response, between 68 and 79 hpf (Easter and Nicola, 1996, 1997).

To determine the time course of PMR development, we examined zebrafish behavior between $21 \mathrm{hpf}$ and $50 \mathrm{hpf}$. We find that the magnitude of PMR excitation develops rapidly between 28 and 30 hpf: after the start of touch-evoked coiling and before the optokinetic reflex (Fig. 3a). The PMR excitation phase lasts for $\sim 10 \mathrm{~h}$ between 30 and 40 hpf. At 40 hpf, the magnitude of PMR excitation begins a gradual decline and eventually disappears by $50 \mathrm{hpf}$ (Fig. $3 a$ ). Interestingly, we find evidence of photo-sensation even before $30 \mathrm{hpf}$. Although light does not trigger PMR excitation at $27 \mathrm{hpf}$, it does trigger the PMR inactive phase (Fig. $3 a, b$ ). For example, even in the absence of PMR excitation, light significantly reduces motor activity (Fig. 3b). These are the earliest reported behavioral responses to light in the zebrafish. Because zebrafish develop their b
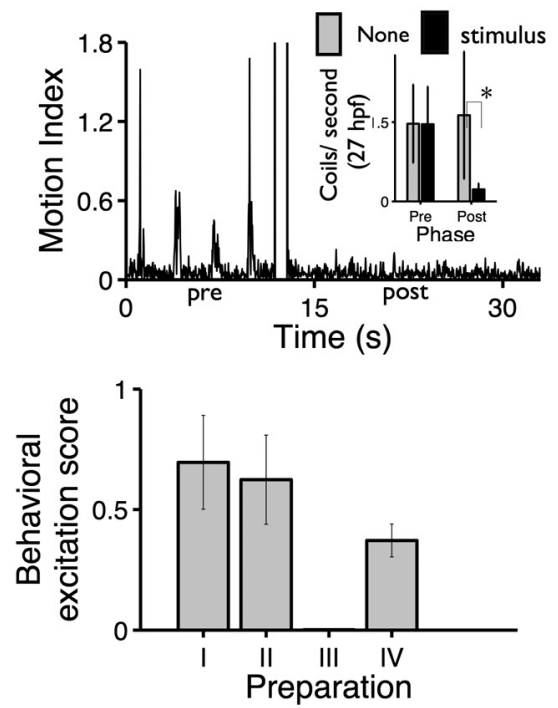

d

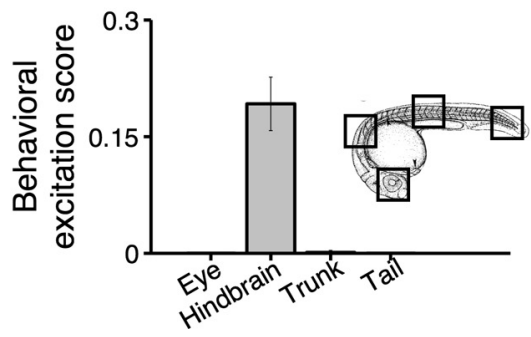

Figure 3. The PMR is a nonvisual photic behavior. $\boldsymbol{a}$, Line plot showing behavioral excitation scores of animals tested at the indicated developmental ages ( $n=10$ wells). $\boldsymbol{b}$, The bar plot quantifies average coils per second in $27 \mathrm{hpf}$ animals before (pre) and after (post) stimulation ( $n=9$ animals per group). The difference between prestimulation and poststimulation in light-treated

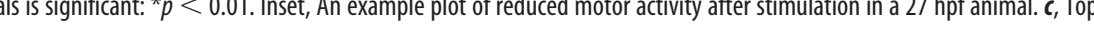
fransections. Preparation II lacks all forebrain and midbrain structures but retains the posterior hindbrain. Preparation III lacks al Reduced excitation score in tailless fish (preparation IV) is the result of fewer moving pixels in these truncated animals. $\boldsymbol{d}$, Top, scores of animals stimulated at the indicated locations ( $n=3$ animals, each animal stimulated in every condition). The difference between the group receiving hindbrain stimulation all other groups is significant: $p<0.001$. Data are mean \pm SD.

first signs of vision at $73 \mathrm{hpf}$ (Easter and Nicola, 1997), these data suggest that the PMR behavior is a nonvisual response to light.

The PMR develops $>40$ h before the first functional visual pathways (Brockerhoff et al., 1995; Schmitt and Dowling, 1999; Morris and Fadool, 2005). To determine whether the PMR requires visual photoreceptors, we analyzed the behavior of zebrafish preparations with and without their eyes at $30 \mathrm{hpf}$. Remarkably, blinded preparations, also lacking the pineal organs and other canonical deep brain photosensitive tissues, continued to exhibit robust PMR excitation for many hours after transection (Fig. 3c). Thus, the PMR is a nonvisual photic behavior.

Because the PMR does not require canonical photoreceptive organs, such as the eyes and pineal, we sought to determine where PMR photoreceptors are located anatomically. Dermal melanocytes are intrinsically photosensitive in some amphibians and fish (Wakamatsu et al., 1980). To determine whether melanocytes are necessary to trigger the PMR, we analyzed the behavior of casper mutant zebrafish that fail to develop all melanocytes and iridophores (White et al., 2008). We find that casper mutant embryos exhibit a robust PMR (data not shown), indicating that dermal melanophores are not necessary for the PMR. 
a

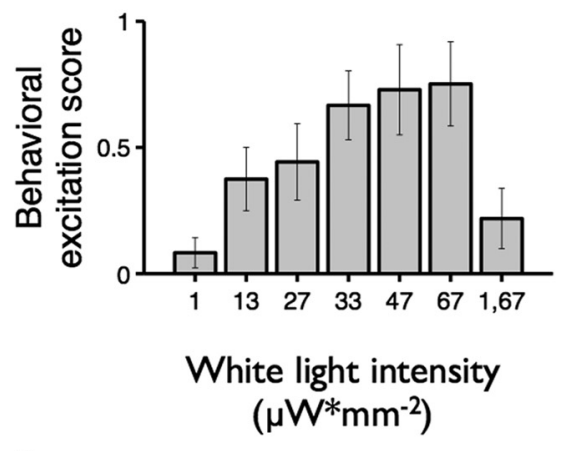

C

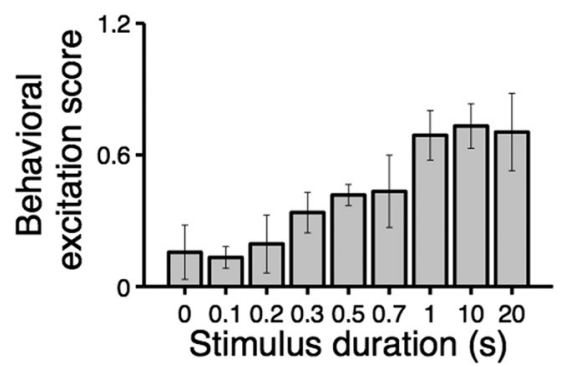

b

\begin{tabular}{|l|c|c|}
\hline $\begin{array}{c}\text { Wavelength } \\
(\mathrm{nm})\end{array}$ & $\begin{array}{c}\text { Intensity } \\
\left(\mu \mathrm{W} / \mathrm{mm}^{2}\right)\end{array}$ & PMR \\
\hline Violet (405) & 15 & - \\
\hline Blue (485) & 15 & + \\
\hline Green (560) & 15 & + \\
\hline Red (650) & 23 & - \\
\hline
\end{tabular}

d

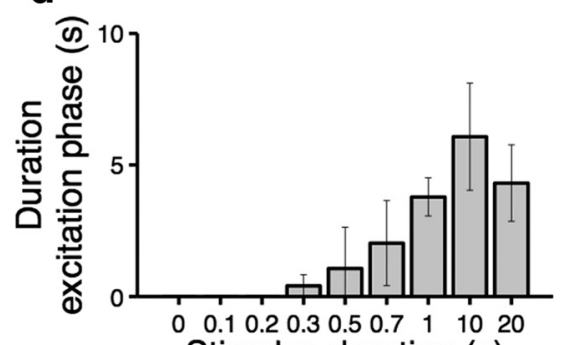

Stimulus duration (s)

Figure 4. The PMR is a response to visible light. $\boldsymbol{a}$, Bar plot showing behavioral excitation scores in response to white light stimuli ( $1 \mathrm{~s}$ ) at the indicated intensity ( $n=10$ ). The difference between the groups treated with 1 and $13 \mu \mathrm{W} / \mathrm{mm}^{2}$ is significant: $p<0.001$. Significantly more activity is elicited by $33 \mu \mathrm{W} / \mathrm{mm}^{2}$ than $13 \mu \mathrm{W} / \mathrm{mm}^{2}: p<0.005 . " 1,67$ " indicates that these animals were preexposed to low levels of ambient light $\left(1 \mu \mathrm{W} / \mathrm{mm}^{2}\right)$ for 10 min before PMR analysis with a $67 \mu \mathrm{W} / \mathrm{mm}^{2}$ stimulus. $\boldsymbol{b}$, Table showing the effects of stimuli at the indicated wavelengths and intensities. + indicates stimuli that trigger PMR excitation; and - , stimuli that did not trigger PMR excitation. $c$, Bar plot showing behavioral excitation scores in response to white light stimuli for the indicated stimulus duration $(n=5)$. An ANOVA showed that the differences between groups exposed to $\leq 0.5$ $s$ are not statistically significant. There is a statistically significant difference between the $0.5 \mathrm{~s}$ treatment group and the 1,10 , and 20 s treatment groups: $p<0.05$. The difference between 0.7 and 10 s is also significant: $p<0.05$. d, Bar plot showing the duration of behavioral excitation in response to stimuli of the indicated duration $(n=5)$. The difference between the 0.1 and 20 s treatment groups is significant: $p<0.001$. Data are mean \pm SD.

Previous reports suggest that nonvisual photic behaviors in lampreys and snakes are triggered by cutaneous photoreceptors in the tail (Young, 1935; Zimmerman and Heatwole, 1990). To determine whether tail photoreceptors are necessary for the zebrafish PMR, we analyzed the PMR in animals lacking the caudal half of their bodies. Tailless animals exhibit a robust PMR, indicating that the tail is not necessary for PMR photo-sensation and that PMR photoreceptors are not located exclusively in the tail (Fig. 3c).

Supraspinal input from the brain is not necessary for spontaneous coiling or touch-evoked coiling behaviors in the zebrafish (Downes and Granato, 2006). To determine whether the hindbrain is required for the PMR, we analyzed the behavior of spinalized animals. We find that spinalized preparations lacking the hindbrain did not respond to photic stimuli (Fig. 3c). Thus, unlike the touch response, supraspinal input from the hindbrain is necessary for the PMR.

Because the hindbrain is necessary for the PMR, we wondered whether it might also be sufficient for sensing photic stimuli. To test this hypothesis, we used confocal microscopy to restrict photic stimulation to the column of cells above and below the eye, hindbrain, trunk, or tail. We find that motor activity is not elicited by photic stimuli restricted to the eye, trunk, or tail (Fig. 3d). By contrast, PMR excitation is strongly and reproducibly elicited by photic stimuli directed at the hindbrain (Fig. 3d). Together, these data suggest that hindbrain neurons are both necessary and sufficient to elicit PMR behaviors.
The PMR is a response to visible light To determine the relationship between stimulus intensity and response magnitude, we exposed dark-adapted animals to white light stimuli $(300-700 \mathrm{~nm})$ from a xenon lamp at various intensities. Whereas $1 \mu \mathrm{W} / \mathrm{mm}^{2}$ is too dim to trigger PMR excitation, a $13 \mu \mathrm{W} / \mathrm{mm}^{2}$ stimulus elicits a significant increase in motor activity ( $p<0.001$; Fig. $4 a$ ). Thus, the minimum intensity needed to trigger PMR excitation is between 1 and $13 \mu \mathrm{W} / \mathrm{mm}^{2}$. Stimulus intensities $\geq 33 \mu \mathrm{W} / \mathrm{mm}^{2}$ trigger significantly more excitation than the minimum effective intensity $(p<0.005$; Fig. $4 a$ ). These data indicate that PMR behaviors are triggered by stimuli $\sim 50 \times$ less intense than direct sunlight $(667 \mu \mathrm{W} /$ $\mathrm{mm}^{2}$ ). Furthermore, these data suggest that PMR behaviors could be triggered by natural stimuli outside the laboratory.

To determine which wavelengths of light are sufficient to trigger the PMR, we exposed animals to violet $(387 \mathrm{~nm})$, blue $(480 \mathrm{~nm})$, green $(560 \mathrm{~nm})$, and red $(650$ $\mathrm{nm}$ ) stimuli. We find that blue and green wavelengths (both $\sim 15 \mu \mathrm{W} / \mathrm{mm}^{2}$ ) reproducibly trigger robust PMR excitation (Fig. 4b). By contrast, neither violet (405 $\mathrm{nm})$ nor red $(650 \mathrm{~nm})$ stimuli $(15 \mu \mathrm{W} /$ $\mathrm{mm}^{2}$ and $23 \mu \mathrm{W} / \mathrm{mm}^{2}$ respectively) triggers PMR excitation (Fig. 4b). These data suggest that the PMR is triggered by blue and green light stimuli, but not by shorter or longer wavelengths.

To determine the duration of light necessary to trigger PMR excitation, we analyzed the behavior of animals exposed to blue light stimuli $\left(480 \mathrm{~nm}, 15 \mu \mathrm{W} / \mathrm{mm}^{2}\right)$ for various durations. We find that the response magnitudes are the same for stimuli lasting 1 or $20 \mathrm{~s}$ (Fig. 4c). Similarly, the maximum response duration is $5-7 \mathrm{~s}$, for stimuli lasting either 1 or $20 \mathrm{~s}$. A 5-7 s response duration is also observed for bright $\left(67 \mu \mathrm{W} / \mathrm{mm}^{2}\right)$ white stimuli lasting 1 or $20 \mathrm{~s}$ (data not shown). These data indicate that PMR excitation has a finite magnitude and duration and does not continue under constant light (Fig. 4d). Together, these data suggest that the minimum stimulus duration for maximum effect is $\sim 1 \mathrm{~s}$.

In larval zebrafish, visual phototaxis behavior is triggered by changes in the relative intensities of field and target stimuli (Burgess et al., 2010). To determine whether PMR behaviors are also triggered by relative changes in light intensity, we preadapted zebrafish embryos to low levels of ambient light $\left(1 \mu \mathrm{W} / \mathrm{mm}^{2}\right)$ for 10 min before PMR analysis. Next, we exposed these lightadapted animals to a large relative increase in brightness. Surprisingly, even very intense stimuli $\left(67 \mu \mathrm{W} / \mathrm{mm}^{2}\right)$ do not trigger PMR excitation in light-adapted animals (Fig. 4a). Thus, unlike visual phototaxis, the PMR depends on dark adaptation, rather than relative changes in light intensity.

\section{A discrete set of hindbrain neurons drive PMR behaviors}

To understand which neurons in the brain may be activated during the PMR, we measured neuronal activity in transgenic zebrafish expressing the genetically encoded fluorescent calcium 


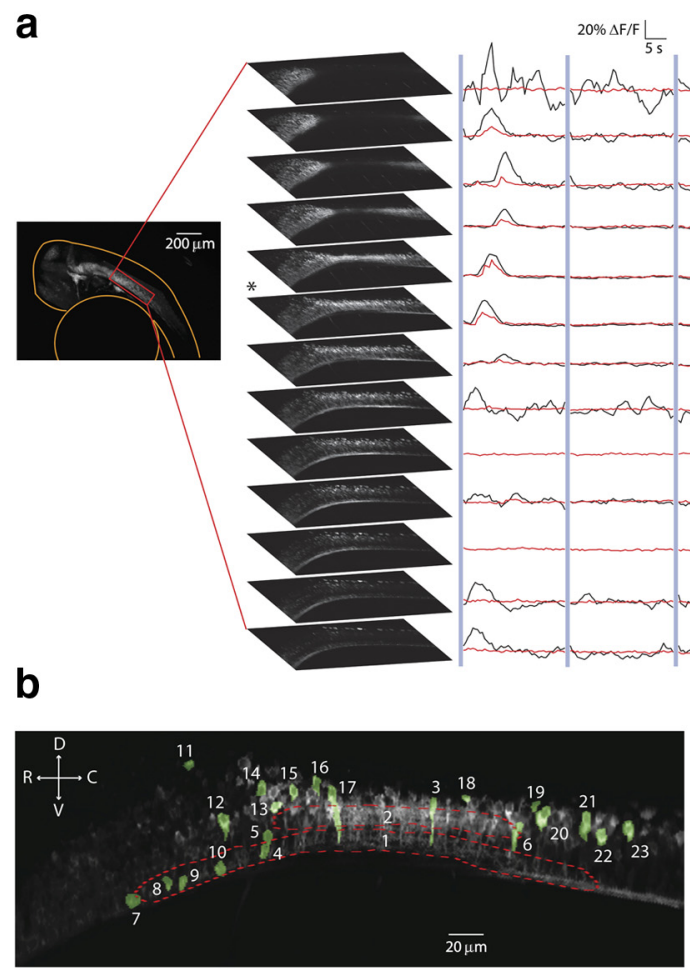

C
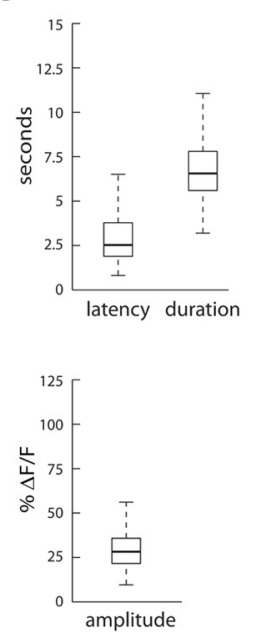

d

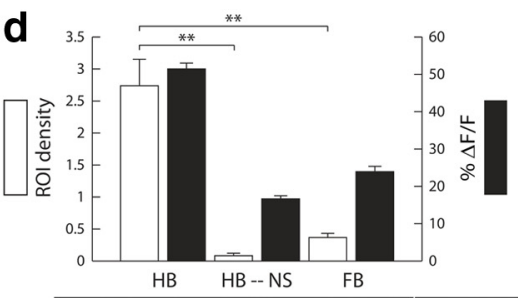

e

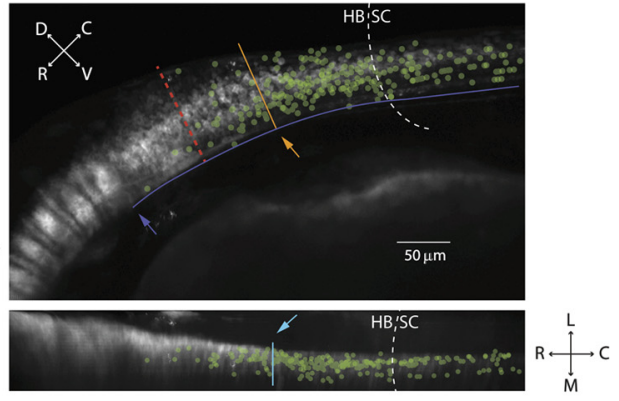

f
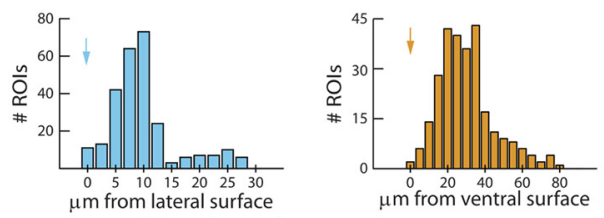
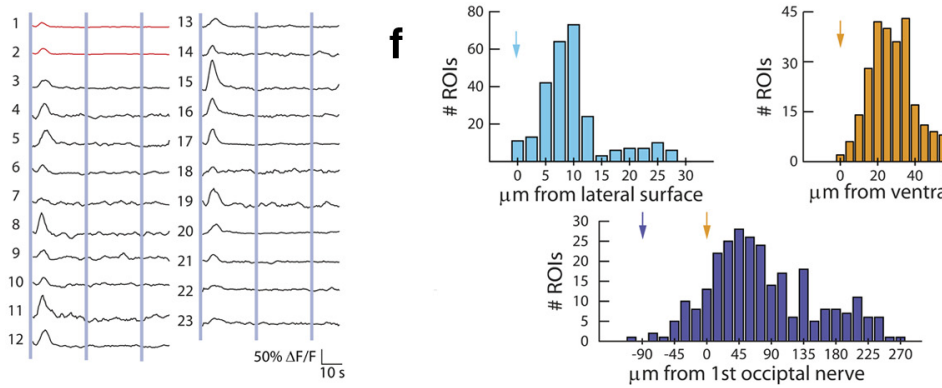

Figure 5. A discrete set of neurons is activated during the PMR. $\boldsymbol{a}$, Left, $3 \mathrm{D}$ projection of a typical $36 \mathrm{hpf}$ embryonic zebrafish brain expressing GCaMP2 under the pan-neuronal HuC $\mathrm{promoter}$. The orange outline indicates the anatomical border of the embryo. Right, Thirteen representative optical slices separated by $3 \mu \mathrm{m}$ in the hindbrain region outlined in red. Neuronal responses to blue light stimulation (bars) are shown beside each slice. Red traces show the change in average fluorescence for the entire slice, and black traces show the smoothed change in fluorescence averaged across all active regions in the slice. $\boldsymbol{b}$, Activated neurons (green) and corresponding smoothed fluorescence changes from a single slice in the same embryo as in $\boldsymbol{a}$. Traces 1 and 2 (red) show representative neuropil responses from the regions outlined by the hyphenated red lines. The image in $\boldsymbol{b}$ corresponds to the plane labeled with " $*$ " in $\boldsymbol{a}$. c, Boxplots showing the distribution of hindbrain neuronal response latencies, durations, and amplitudes during the PMR. ( $n=318-328$ ROls, 7 embryos). $\boldsymbol{d}$, Mean detected neuronal ROI densities (ROls $/ 1000 \mu \mathrm{m}^{3}$, white) and response amplitudes (black) in the hindbrain (HB, 369 ROls, 132 volumes) and forebrain (FB, 56 ROls, 153 volumes) of three 36 hpf embryos. The same quantities are plotted for the hindbrain during trials without stimulus presentation (HB-NS, 11 ROls, 132 volumes). Error bars indicate SEM. ${ }^{* *} p<0.001$ (Student's $t$ test). $e$, Top left, Normalized spatial distribution of detected R0ls $(n=273$, green) from 4 fish overlaid on an average intensity projection of the hindbrain in a typical side-mounted $36 \mathrm{hpfHuC::GCamP2} \mathrm{fish.} \mathrm{Bottom} \mathrm{left,} \mathrm{The} \mathrm{same} \mathrm{spatial} \mathrm{distribution} \mathrm{of} \mathrm{neurons} \mathrm{as} \mathrm{viewed} \mathrm{from} \mathrm{a} \mathrm{top-down} \mathrm{image} \mathrm{reslice.}$ $\boldsymbol{f}$, Top right, orange, Histogram quantifying the spatial distribution of identified ROIs along the D-V axis. Top left, cyan, Histogram quantification of M-L axis. Bottom, blue, R-C axis. Solid lines in $\boldsymbol{e}$ represent the axes used to construct corresponding histograms in $\boldsymbol{f}$. Arrows indicate the starting positions along each axis used for histogram construction. Dotted white lines indicate the hindbrain-spinal cord boundary. For reference, the dotted red line in $\boldsymbol{e}$ delineates the rostral extent of the image in $\boldsymbol{b}$.

indicator GCaMP2 (Diez-Garcia et al., 2007) under the panneuronal HuC promoter (Park et al., 2000). By monitoring the neuronal fluorescence changes elicited by photic stimuli with two-photon laser scanning microscopy, we were able to identify the specific location of neurons involved in the PMR (Fig. $5 a$ ). In 7 responsive $32-38 \mathrm{hpf}$ fish, neurons in the caudal hindbrain, but not in the forebrain or midbrain, showed robust excitation to the photic stimulus, consistent with the hypothesis that supraspinal input is necessary to drive PMR behaviors. Figure $5 b$ shows that, in one representative animal, 21 neurons and 2 distinct fiber tracts fire synchronously during the PMR, illustrating the common pattern of excitation in response to the photic stimulus (Fig. $5 b$ ). By pooling the normalized positions of identified ROIs across responsive fish, we show that active neurons are distributed throughout the caudal hindbrain (Fig. 5e), with the highest frequency of active neurons in Ro8, $\sim 45 \mu \mathrm{m}$ caudal to the first occipital nerve (Fig. $5 f$, bottom, blue). ROIs also cluster with greatest frequency $35 \mu \mathrm{m}$ from the ventral surface on the brain (Fig. $5 f$, top right, orange) and $10 \mu \mathrm{m}$ from the lateral surface of the brain (Fig. $5 f$, top left, cyan). Some PMR-correlated neuronal activity was also observed in the anterior spinal cord (Fig. $5 e$, hyphenated line). All observed neuronal responses are likely to correspond to the PMR because activity is consistently locked to stimulus onset with a fixed latency and can only be observed after the first stimulus after a long refractory period. Across all identified ROIs, the median time to fluorescence onset was $2.5 \mathrm{~s}$, and the median duration of the calcium response was $6 \mathrm{~s}$ (Fig. $5 c$ ), in close agreement with the latencies and durations of the coiling and swimming events that occur during PMR excitation (Figs. 1 and 2). When hindbrain activity is compared with forebrain activity during stimulus trials, a pronounced difference in both the density of identified ROIs and the amplitude of detected responses emerges (Fig. $5 d$ ). These data support the conclusion that the PMR stimulus specifically recruits neurons in the hindbrain. Furthermore, the density of responsive ROIs in the hindbrain during stimulus trials is significantly different from the density during no stimulus trials. These data reiterate that hindbrain responses during stimulus presentation are stimulus-evoked and not artifacts of the experimental preparation (e.g., two-photon scanning). The few hindbrain responses detected during no stimulus trials most likely reflect baseline spontaneous activity in hindbrain circuits. Because of limitations of the calcium sensor, it 

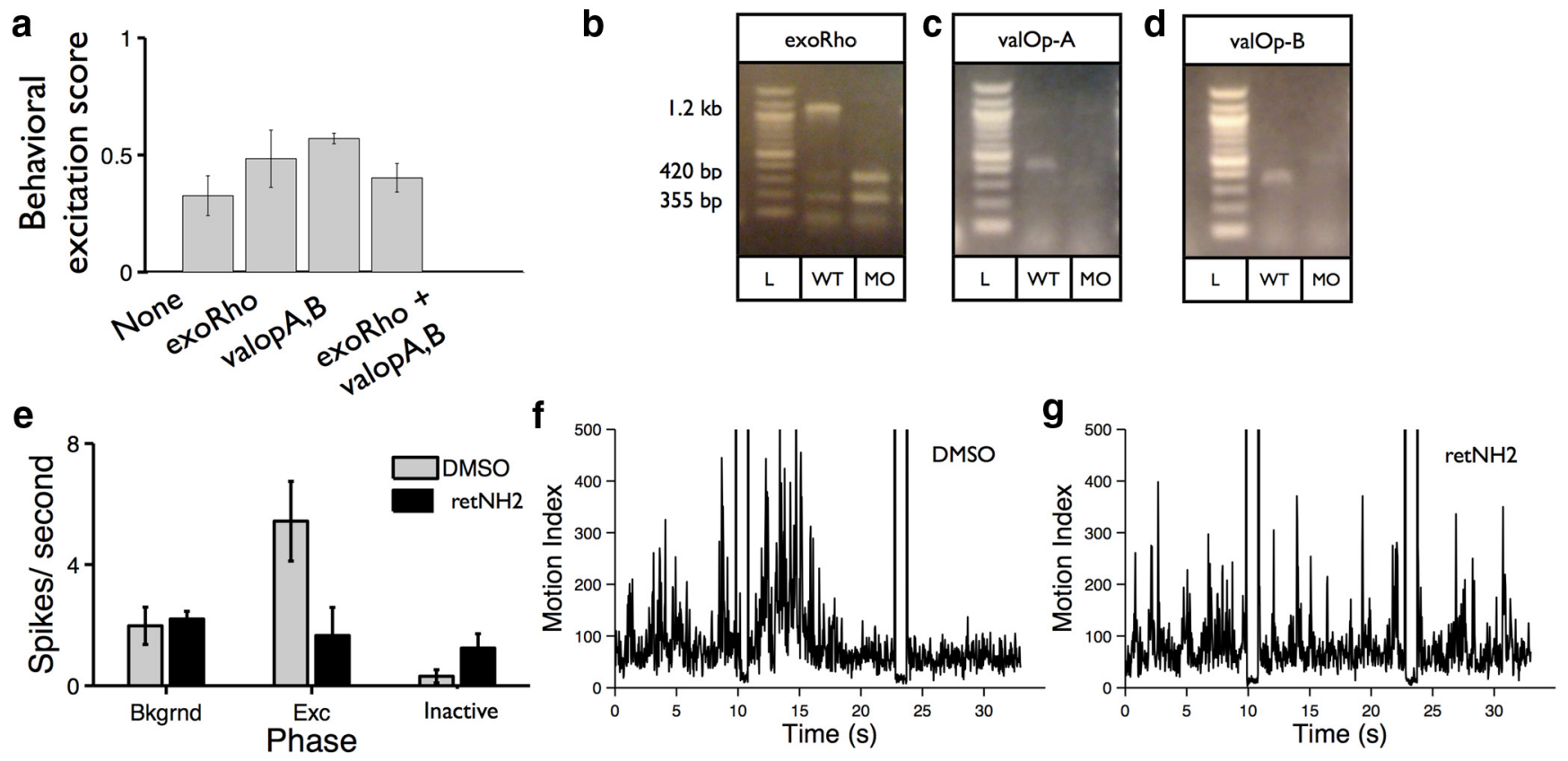

Figure 6. Opsin phototransduction is necessary for photomotor excitation. $\boldsymbol{a}$, Bar plot showing behavioral excitation scores of uninjected controls (None), and animals injected with morpholinos targeting exorhodopsin (exRho), valopsin A, and valopsin B (valopA,B), and the three opsins together (exoRho + valopA,B) ( $n=5$ wells, 10 animals per well). Morphant scores are not significantly less than the controls. $\boldsymbol{b}-\boldsymbol{d}$, Gel images showing the efficacy of the splice blocking morpholinos tested in $\boldsymbol{a}$. $\boldsymbol{e}$, Bar plot showing number of motion index spikes per second of animals treated with DMSO, or the opsin inhibitor retNH2 $(n=5)$. For DMSO-treated control animals, spike rate is significantly greater during the excitation phase (Exc) and significantly lower during the inactive phase (Inactive) compared with background (Bkgrnd). $p<0.01$. For retNH2-treated animals, spike rate is not significantly different during any of the phases. Examples from animals treated with DMSO $(\boldsymbol{f})$, or retNH2 $(\boldsymbol{g})$ are shown.

remains possible that we are underestimating the number and distribution of responsive neurons. Nonetheless, the anatomical clustering of identified ROIs, coupled with the similarity of neuronal response and behavioral response parameters, suggests that a discrete set of hindbrain neurons drive PMR motor activity.

\section{Opsins are necessary for the PMR}

Vertebrate photosensation requires the opsins, a large family of retinal-based G-protein-coupled receptors (Peirson et al., 2009). To determine whether neurons in the zebrafish hindbrain sense photic stimuli via opsin-based phototransduction, we analyzed the effects on opsin impairment on PMR behavior. The zebrafish genome encodes $>10$ extra-retinal opsins with different expression patterns and functions, including at least 5 melanopsin isoforms (Matos-Cruz et al., 2011). We chose 3 candidate opsin genes for further analysis, including exo-rhodopsin, valopsinA, and valopsinB (Kojima et al., 2008). To determine whether these candidate opsins are necessary for the PMR, we used antisense morpholinos to knock-down their expression. We find that PMR excitation is not reduced in the morphant animals, suggesting that these opsins are not necessary for PMR excitation (Fig. 6a).

The visual retinoid cycle depends on 11-cis-retinal. To determine whether the visual cycle is necessary for the PMR, we treated animals with the small-molecule Ret-NH2, which inhibits synthesis of 11-cis-retinal in the zebrafish (Schonthaler et al., 2007). We find that Ret-NH2-treated animals fail to exhibit PMR behaviors, including the PMR excitation and inactive phases (Fig. 6bd). Importantly, Ret-NH2-treated animals appear otherwise normal, showing normal background motion and touch response. Melanopsin-based photoreception is independent of the visual retinoid cycle (Tu et al., 2006), suggesting that melanopsin is not necessary for PMR excitation. Because PMR excitation appears to depend on the visual cycle, these data suggest that the PMR is mediated by one or more opsins in the nervous system.

\section{Discussion}

Here, we have described the molecular, cellular, and behavioral mechanisms of the zebrafish PMR. The PMR behavior is the first photic behavior linked to light-sensitive neurons in the vertebrate hindbrain and the earliest known photic behavior to develop in the zebrafish. At least three attributes distinguish the PMR from other previously reported behaviors in the zebrafish. First, the PMR latency and refractory phases are orders of magnitude longer than those observed for other stimuli. For example, the previously reported latency and refractory periods for responses to acoustic, tactile, and photic stimuli are milliseconds in duration (Saint-Amant and Drapeau, 1998; Burgess and Granato, 2007a, b; Best et al., 2008), whereas the PMR latency and refractory phases last for seconds and minutes, respectively. Second, the neuroanatomical requirements of the PMR are distinct from other behaviors that occur at this time in development. For example, supraspinal input is necessary for the PMR, unlike spontaneous coiling, touch-evoked coiling, and touch-evoked swimming (Downes and Granato, 2006). Finally, the PMR depends on nonocular photoreceptors, unlike other photic behaviors, such as the light adaptation response (Burgess and Granato, 2007a), optokinetic response (Rick et al., 2000), and the visualmotor response (Emran et al., 2007).

It appears that the early zebrafish embryo has a limited repertoire of motor responses consisting of coils and swims and that these motor responses can be differentially recruited by specific upstream circuits (Saint-Amant and Drapeau, 1998, 2000; Brustein et al., 2003). Whereas touch stimuli elicit brief coiling and swimming events, the PMR evokes coils and swims with long 
latency and long duration. Because hindbrain neurons link sensory input to motor output, they provide an excellent starting point for studying the underlying circuitry of this complex series of behaviors.

Most behavioral reflexes in the zebrafish have very short refractory periods (milliseconds). By contrast, the minimum interstimulus interval for maximum PMR excitation is several orders of magnitude longer (10 min). One possible explanation for this long refractory phase is opsin photobleaching. Most opsins use cis-to-trans isomerization of the retinaldehyde chromophore as the primary photoreceptive event and must regenerate the cischromophore to regain photosensitivity. Recovery from photobleaching occurs over a similar time scale as the PMR refractory phase (10 min) (Sexton et al., 2012), suggesting that photobleaching may explain the 10 min interstimulus interval between PMR excitation phases.

Different mechanisms may control the PMR excitation and inactive/refractory phases. We show that light stimuli inhibit spontaneous coiling activity at $27 \mathrm{hpf}$ without eliciting PMR excitation. At $27 \mathrm{hpf}$, spontaneous coils are generated and propagated by an extensive network of neurons interconnected in the spinal cord by gap junctions (Saint-Amant and Drapeau, 2001). Spontaneous coils are independent of chemical synaptic transmission and are dependent on electrical coupling of the neuronal network within the spinal cord (Saint-Amant and Drapeau, 2001). At $27 \mathrm{hpf}$, inhibitory signals from the PMR cells may be sufficient to block spontaneous coiling. By $32 \mathrm{hpf}$, the nervous system may develop additional synaptic inputs that drive the PMR excitation phase. One possibility is that each phase may be controlled by independent photoreceptors.

Opsin-based phototransduction is based on photoisomerization of the chromophore 11-cis-retinal to all-trans-retinal. Chromophore regeneration, via the retinoid cycle, is necessary to restore photoreceptors to their dark-adapted state. The smallmolecule Ret-NH2 is a potent and selective inhibitor of chromophore regeneration (Golczak et al., 2005) that reduces levels of 11-cis-retinal in wild-type zebrafish (Schonthaler et al., 2007). We find that Ret-NH2 blocks PMR behaviors, suggesting that opsin-based phototransduction is necessary for these nonvisual photic responses. However, exactly which opsin or opsins are necessary for PMR behaviors remains unclear. Morpholino knockdown of six candidate genes did not block the PMR, suggesting that an untested opsin or multiple redundant opsins may control PMR behaviors.

What adaptive purpose might the PMR serve for fish in the wild? Similar nonvisual photic behaviors have been previously described in lampreys (Young, 1935), C. elegans (Edwards et al., 2008; Liu et al., 2010), and Drosophila (Xiang et al., 2010). In these animals, nonvisual light-induced motor behaviors appear to function as an escape response to keep animals hidden from dangerous UV radiation or predators (Xiang et al., 2010). The PMR is likely to serve a different purpose in zebrafish because it only occurs before hatching, when the chorion prevents animals from swimming away. One possibility is that the PMR is a consequence of irradiance detection mechanisms with alternative primary functions. For example, it may be useful for animals to modulate neuronal excitability based on environmental light levels. Alternatively, the PMR may be an evolutionarily vestige with important ancestral functions in other organisms. Overall, the PMR presents new opportunities to understand the development and function of vertebrate nonvisual photobiology and may improve our understanding of how the nervous system responds to light.

\section{References}

Ahrens MB, Li JM, Orger MB, Robson DN, Schier AF, Engert F, Portugues R (2012) Brain-wide neuronal dynamics during motor adaptation in zebrafish. Nature 485:471-477. CrossRef Medline

Asaoka Y, Mano H, Kojima D, Fukada Y (2002) Pineal expressionpromoting element (PIPE), a cis-acting element, directs pineal-specific gene expression in zebrafish. Proc Natl Acad Sci U S A 99:15456-15461. CrossRef Medline

Becker HE, Cone RA (1966) Light-stimulated electrical responses from skin. Science 154:1051-1053. CrossRef Medline

Berson DM, Dunn FA, Takao M (2002) Phototransduction by retinal ganglion cells that set the circadian clock. Science 295:1070-1073. CrossRef Medline

Best JD, Berghmans S, Hunt JJ, Clarke SC, Fleming A, Goldsmith P, Roach AG (2008) Non-associative learning in larval zebrafish. Neuropsychopharmacology 33:1206-1215. CrossRef Medline

Blackshaw S, Snyder SH (1997) Parapinopsin, a novel catfish opsin localized to the parapineal organ, defines a new gene family. J Neurosci 17:8083-8092. Medline

Brockerhoff SE, Hurley JB, Janssen-Bienhold U, Neuhauss SC, Driever W, Dowling JE (1995) A behavioral screen for isolating zebrafish mutants with visual system defects. Proc Natl Acad Sci U S A 92:10545-10549. CrossRef Medline

Brustein E, Saint-Amant L, Buss RR, Chong M, McDearmid JR, Drapeau P (2003) Steps during the development of the zebrafish locomotor network. J Physiol Paris 97:77-86. CrossRef Medline

Burgess HA, Granato M (2007a) Modulation of locomotor activity in larval zebrafish during light adaptation. J Exp Biol 210:2526-2539. CrossRef Medline

Burgess HA, Granato M (2007b) Sensorimotor gating in larval zebrafish. J Neurosci 27:4984-4994. CrossRef Medline

Burgess HA, Schoch H, Granato M (2010) Distinct retinal pathways drive spatial orientation behaviors in zebrafish navigation. Curr Biol 20:381386. CrossRef Medline

Denk W, Strickler JH, Webb WW (1990) Two-photon laser scanning fluorescence microscopy. Science 248:73-76. CrossRef Medline

Diez-Garcia J, Akemann W, Knöpfel T (2007) In vivo calcium imaging from genetically specified target cells in mouse cerebellum. Neuroimage 34 : 859-869. CrossRef Medline

Downes GB, Granato M (2006) Supraspinal input is dispensable to generate glycine-mediated locomotive behaviors in the zebrafish embryo. J Neurobiol 66:437-451. CrossRef Medline

Drapeau P, Ali DW, Buss RR, Saint-Amant L (1999) In vivo recording from identifiable neurons of the locomotor network in the developing zebrafish. J Neurosci Methods 88:1-13. CrossRef Medline

Easter SS Jr, Nicola GN (1996) The development of vision in the zebrafish (Danio rerio). Dev Biol 180:646-663. CrossRef Medline

Easter SS Jr, Nicola GN (1997) The development of eye movements in the zebrafish (Danio rerio). Dev Psychobiol 31:267-276. CrossRef Medline

Edwards SL, Charlie NK, Milfort MC, Brown BS, Gravlin CN, Knecht JE, Miller KG (2008) A novel molecular solution for ultraviolet light detection in Caenorhabditis elegans. PLoS Biol 6:e198. CrossRef Medline

Emran F, Rihel J, Adolph AR, Wong KY, Kraves S, Dowling JE (2007) OFF ganglion cells cannot drive the optokinetic reflex in zebrafish. Proc Natl Acad Sci U S A 104:19126-19131. CrossRef Medline

Fernandes AM, Fero K, Arrenberg AB, Bergeron SA, Driever W, Burgess HA (2012) Deep brain photoreceptors control light-seeking behavior in zebrafish larvae. Curr Biol 22:2042-2047. CrossRef Medline

Golczak M, Kuksa V, Maeda T, Moise AR, Palczewski K (2005) Positively charged retinoids are potent and selective inhibitors of the trans-cis isomerization in the retinoid (visual) cycle. Proc Natl Acad Sci U S A 102:8162-8167. CrossRef Medline

Hamill OP, Marty A, Neher E, Sakmann B, Sigworth FJ (1981) Improved patch-clamp techniques for high-resolution current recording from cells and cell-free membrane patches. Pflugers Arch 391:85-100. CrossRef Medline

Harth MS, Heaton MB (1973) Nonvisual photic responsiveness in newly hatched pigeons (Columba livia). Science 180:753-755. CrossRef Medline

Hattar S, Lucas RJ, Mrosovsky N, Thompson S, Douglas RH, Hankins MW, Lem J, Biel M, Hofmann F, Foster RG, Yau KW (2003) Melanopsin and rod-cone photoreceptive systems account for all major accessory visual functions in mice. Nature 424:76-81. CrossRef Medline 
Heaton MB, Harth MS (1974) Non-visual light responsiveness in the pigeon: developmental and comparative considerations. J Exp Zool 188: 251-264. CrossRef Medline

Kojima D, Mano H, Fukada Y (2000) Vertebrate ancient-long opsin: a green-sensitive photoreceptive molecule present in zebrafish deep brain and retinal horizontal cells. J Neurosci 20:2845-2851. Medline

Kojima D, Torii M, Fukada Y, Dowling JE (2008) Differential expression of duplicated VAL-opsin genes in the developing zebrafish. J Neurochem 104:1364-1371. CrossRef Medline

Kokel D, Bryan J, Laggner C, White R, Cheung CY, Mateus R, Healey D, Kim S, Werdich AA, Haggarty SJ, Macrae CA, Shoichet B, Peterson RT (2010) Rapid behavior-based identification of neuroactive small-molecules in the zebrafish. Nat Chem Biol 6:231-237. CrossRef Medline

Krøvel AV, Olsen LC (2002) Expression of a vas::EGFP transgene in primordial germ cells of the zebrafish. Mech Dev 116:141-150. CrossRef Medline

Liu J, Ward A, Gao J, Dong Y, Nishio N, Inada H, Kang L, Yu Y, Ma D, Xu T, Mori I, Xie Z, Xu XZ (2010) C. elegans phototransduction requires a G protein-dependent cGMP pathway and a taste receptor homolog. Nat Neurosci 13:715-722. CrossRef Medline

Lowery LA, Sive H (2005) Initial formation of zebrafish brain ventricles occurs independently of circulation and requires the nagie oko and snakehead/atplala. 1 gene products. Development 132:2057-2067. CrossRef Medline

Lucas RJ, Freedman MS, Muñoz M, Garcia-Fernández JM, Foster RG (1999) Regulation of the mammalian pineal by non-rod, non-cone, ocular photoreceptors. Science 284:505-507. CrossRef Medline

Mano H, Kojima D, Fukada Y (1999) Exo-rhodopsin: a novel rhodopsin expressed in the zebrafish pineal gland. Brain Res Mol Brain Res 73:110118. CrossRef Medline

Matos-Cruz V, Blasic J, Nickle B, Robinson PR, Hattar S, Halpern ME (2011) Unexpected diversity and photoperiod dependence of the zebrafish melanopsin system. PloS One 6:e25111. CrossRef Medline

Max M, McKinnon PJ, Seidenman KJ, Barrett RK, Applebury ML, Takahashi JS, Margolskee RF (1995) Pineal opsin: a nonvisual opsin expressed in chick pineal. Science 267:1502-1506. CrossRef Medline

Mikut OB, Braun S, Reischl M (2008) The open source Matlab toolbox Gait-CAD and its application to bioelectric signal processing. In: Proc, DGBMT-Workshop Biosignalverarbeitung, pp 109-111. Potsdam, Germany.

Morris AC, Fadool JM (2005) Studying rod photoreceptor development in zebrafish. Physiol Behav 86:306-313. CrossRef Medline

Nakane Y, Ikegami K, Ono H, Yamamoto N, Yoshida S, Hirunagi K, Ebihara S, Kubo Y, Yoshimura T (2010) A mammalian neural tissue opsin (Op$\sin 5$ ) is a deep brain photoreceptor in birds. Proc Natl Acad Sci U S A 107:15264-15268. CrossRef Medline

Noseda R, Kainz V, Jakubowski M, Gooley JJ, Saper CB, Digre K, Burstein R (2010) A neural mechanism for exacerbation of headache by light. Nat Neurosci 13:239-245. CrossRef Medline

Okano T, Yoshizawa T, Fukada Y (1994) Pinopsin is a chicken pineal photoreceptive molecule. Nature 372:94-97. CrossRef Medline

Park HC, Kim CH, Bae YK, Yeo SY, Kim SH, Hong SK, Shin J, Yoo KW, Hibi M, Hirano T, Miki N, Chitnis AB, Huh TL (2000) Analysis of upstream elements in the $\mathrm{HuC}$ promoter leads to the establishment of transgenic zebrafish with fluorescent neurons. Dev Biol 227:279-293. CrossRef Medline

Peirson SN, Halford S, Foster RG (2009) The evolution of irradiance detection: melanopsin and the non-visual opsins. Philos Trans R Soc Lond Biol Sci 364:2849-2865. CrossRef Medline

Provencio I, Jiang G, De Grip WJ, Hayes WP, Rollag MD (1998) Melanopsin: an opsin in melanophores, brain, and eye. Proc Natl Acad Sci U S A 95:340-345. CrossRef Medline
Reppert SM, Weaver DR (2001) Molecular analysis of mammalian circadian rhythms. Annu Rev Physiol 63:647-676. CrossRef Medline

Ribera AB, Nüsslein-Volhard C (1998) Zebrafish touch-insensitive mutants reveal an essential role for the developmental regulation of sodium current. J Neurosci 18:9181-9191. Medline

Rick JM, Horschke I, Neuhauss SC (2000) Optokinetic behavior is reversed in achiasmatic mutant zebrafish larvae. Curr Biol 10:595-598. CrossRef Medline

Ridge KD, Abdulaev NG, Sousa M, Palczewski K (2003) Phototransduction: crystal clear. Trends Biochem Sci 28:479-487. CrossRef Medline

Saint-Amant L, Drapeau P (1998) Time course of the development of motor behaviors in the zebrafish embryo. J Neurobiol 37:622-632. CrossRef Medline

Saint-Amant L, Drapeau P (2000) Motoneuron activity patterns related to the earliest behavior of the zebrafish embryo. J Neurosci 20:3964-3972. Medline

Saint-Amant L, Drapeau P (2001) Synchronization of an embryonic network of identified spinal interneurons solely by electrical coupling. Neuron 31:1035-1046. CrossRef Medline

Schmitt EA, Dowling JE (1999) Early retinal development in the zebrafish, Danio rerio: light and electron microscopic analyses. J Comp Neurol 404: 515-536. CrossRef Medline

Schonthaler HB, Lampert JM, Isken A, Rinner O, Mader A, Gesemann M, Oberhauser V, Golczak M, Biehlmaier O, Palczewski K, Neuhauss SC, von Lintig J (2007) Evidence for RPE65-independent vision in the conedominated zebrafish retina. Eur J Neurosci 26:1940-1949. CrossRef Medline

Sexton TJ, Golczak M, Palczewski K, Van Gelder RN (2012) Melanopsin is highly resistant to light and chemical bleaching in vivo. J Biol Chem 287:20888-20897. CrossRef Medline

Tu DC, Owens LA, Anderson L, Golczak M, Doyle SE, McCall M, Menaker M, Palczewski K, Van Gelder RN (2006) Inner retinal photoreception independent of the visual retinoid cycle. Proc Natl Acad Sci U S A 103:1042610431. CrossRef Medline

Vigh B, Manzano MJ, Zádori A, Frank CL, Lukáts A, Röhlich P, Szel A, Dávid C (2002) Nonvisual photoreceptors of the deep brain, pineal organs and retina. Histol Histopathol 17:555-590. Medline

Wakamatsu Y, Kawamura S, Yoshizawa T (1980) Light-induced pigment aggregation in cultured fish melanophores: spectral sensitivity and inhibitory effects of theophylline and cyclic adenosine- $3^{\prime}, 5^{\prime}$-monophosphate. J Cell Sci 41:65-74. Medline

White RM, Sessa A, Burke C, Bowman T, LeBlanc J, Ceol C, Bourque C, Dovey M, Goessling W, Burns CE, Zon LI (2008) Transparent adult zebrafish as a tool for in vivo transplantation analysis. Cell Stem Cell 2:183-189. CrossRef Medline

Xiang Y, Yuan Q, Vogt N, Looger LL, Jan LY, Jan YN (2010) Lightavoidance-mediating photoreceptors tile the Drosophila larval body wall. Nature 468:921-926. CrossRef Medline

Yoshikawa T, Okano T, Oishi T, Fukada Y (1998) A deep brain photoreceptive molecule in the toad hypothalamus. FEBS Lett 424:69-72. CrossRef Medline

Young JZ (1935) The photoreceptors of lampreys: I. Light-sensitive fibres in the lateral line nerves. J Exp Biol 12:229-238.

Zaidi FH, Hull JT, Peirson SN, Wulff K, Aeschbach D, Gooley JJ, Brainard GC, Gregory-Evans K, Rizzo JF 3rd, Czeisler CA, Foster RG, Moseley MJ, Lockley SW (2007) Short-wavelength light sensitivity of circadian, pupillary, and visual awareness in humans lacking an outer retina. Curr Biol 17:2122-2128. CrossRef Medline

Zimmerman K, Heatwole H (1990) Cutaneous photoreception: a new sensory mechanism for reptiles. Copeia 3:860-862. 